\title{
EXPERIMENT IN CREATING PROFESSIONALLY ORIENTED MATERIALS FOR TEACHING ENGLISH TO INTERNATIONAL LAW STUDENTS
}

\author{
N.N. Dianina, M.A. Kolosovskaia, E.A. Lisova, N.A. Segeitcheva \\ Moscow State Institute of International Relations (University), \\ 76, Prospect Vernadskogo, Moscow, 119454, Russia
}

\begin{abstract}
The study presents results of many years of research and analysis into the process of creating core textbooks and teaching materials aimed at developing linguistic, communicative and professional competences inherent in the future professional activities of International Law students. When creating language learning materials with a focus on a particular profession (e.g. English for Law Students), it is important to proceed from the nature and specific content of day-to-day activities surrounding the future job of a student. Detailed analysis of legal documents and professional activities that International Law students may be involved in in the future allows to gauge the necessary level of English grammar and vocabulary that needs to be attained. The process also points out what specific language and communication skills (e.g. negotiation, persuasion, etc.) as well as professional competencies may be required. Since core textbook for learning English written by native speakers are very generic and, naturally, do not aim at achieving the level of English language, communication and professional skills required by those specializing in International Law, we find it of vital importance to create a series of very niche textbooks for achieving these goals. The present study allows us to determine the structure and content of core textbooks and to create a system of grammar and lexical exercises as well communication tasks aimed at acquiring specific grammar and conversational skills within a short period of time. Of particular mention here too is mastering debating skills, which is paramount for International Law students. This again can only be achieved by creating very narrowly focused materials that will introduce these skills gradually.
\end{abstract}

Keywords: professionally oriented materials, professional activities, professional skills, translation, requirements for exercises, professionally oriented discussion, acquiring debating skills

For citation: Dianina, N.N., Kolosovskaia, M.A., Lisova, E.A., Segeitcheva, N.A. (2021). Experiment in Creating Professionally Oriented Materials for Teaching English to International Law Students. Linguistics \& Polyglot Studies, 7(5), pp. 76-87. https://doi.org/10.24833/2410-2423-2021-5-29-76-87 


\title{
ОПЫТ СОЗДАНИЯ ПРОФЕССИОНАЛЬНО ОРИЕНТИРОВАННЫХ МАТЕРИАЛОВ ДЛЯ ОБУЧЕНИЯ АНГЛИЙСКОМУ ЯЗЫКУ ЮРИСТОВ-МЕЖДУНАРОДНИКОВ
}

\author{
Н.Н. Дианина, М.А. Колосовская, Е.А. Лисова, Н.А. Сергейчева
}

Московский государственный институт международных отношений (университет) МИД России, 119454, Россия, Москва, пр. Вернадского, 76

\begin{abstract}
Аннотация. В статье рассматриваются результаты многолетнего исследования и анализа работы по созданию базовых учебников и учебных пособий, направленных на бормирование лингвистических, коммуникативньх и профессиональных компетениий юриста-международника. При создании профессионально ориентированных учебных материалов необходимо исходить из характера и конкретного наполнения пробессиональной деятельности будущего специалиста. Анализ юридических документов и профессиональной деятельности юриста-международника позволяет определить объём грамматического и лексического материала, необходимого и достаточного для успешной профессиональной деятельности юриста-международника, а также выделить языковые, коммуникативные и профессиональные компетенции, формирование которых необходимо осуществить в ходе обучения английскому языку. Поскольку учебные материалы, написанные носителями английского языка, не ставят себе иелью формирование лингвистических и коммуникативных компетениий до уровня, необходимого юристу-международнику, представляется необходимым создание серии учебников, направленных на достижение указанных иелей. На основе данных проведённого исследования можно определить содержание и структуру учебных материалов, построить оригинальную систему грамматических, лексических и коммуникативных упражнений, позволяющих в сжатые сроки сбормировать прочные грамматические навыки и речевые умения. Особого внимания требует формирование дискуссионных умений как основы профессиональных компетениий юриста-международника. Эта задача может быть выполнена на основе специально разработанных учебных материалов, позволяющих осуществлять поэтапное формирование данных умений.
\end{abstract}

Ключевые слова: профессионально ориентированные материаль, профессиональная деятельность, пробессиональные компетениии, перевод, требования к упражнениям, пробессионально ориентированная дискуссия, формирование дискуссионных умений

Для цитирования: Дианина Н.Н., Колосовская М.А., Лисова Е.А., Сергейчева Н.А. (2021). Опыт создания профессионально ориентированных материалов для обучения английскому языку юристов-международников. Филологические науки в МГИМО. 7(5), С. 76-87. https://doi. org/10.24833/2410-2423-2021-5-29-76-87

$\mathrm{O}$ бучение английскому языку юристов-международников предполагает два основных этапа, представляющих собой практически две отдельные дисциплины - «Иностранный язык общий» и «Язык специальности». Базовый общий курс формирует лингвистические и коммуникативные компетенции, необходимые и достаточные для практической деятельности юриста-международника, а специальный курс знакомит студентов с юридическими поня- 
тиями и категориями, принятыми в англо-американской правовой системе, и формирует навыки переводческой деятельности.

Целью данной статьи является определение содержания и структуры учебных материалов общеязыковой практики, закладывающих основу для успешного усвоения материалов специального курса и формирования профессиональных компетенций юриста-международника.

Актуальность исследования и обмена опытом в данной области определяется тем, что в настоящее время (по мнению как школьных учителей, так и преподавателей вузов) качество языковой подготовки в школах, а следовательно, и абитуриентов вузов значительно снизилось. Это приводит нас к необходимости создания новых учебных материалов, позволяющих в сжатые сроки формировать лингвистические и коммуникативные компетенции на достаточно высоком уровне.

Важно и то, что большинство исследований в области профессионализации обучения иностранному языку (в частности работы Н.П. Хомяковой [14] и К.Х. Рекош [13]) посвящено разделу языка специальности. Вопросы ранней профессионализации в ходе общеязыковой подготовки рассматриваются в исследованиях А.А. Кизимы [10], М.В. Гринёвой [4], А.Н. Павловой [12]. Однако данные работы посвящены обучению экономистов-международников. Безусловно, они указывают основные пути ранней профессионализации обучения, но даже поверхностный взгляд на проблему даёт основания полагать, что обучение юристов-международников должно иметь свои собственные специфические черты. Данное положение и обуславливает цель данной работы, для достижения которой было необходимо решить следующие задачи:

1. Определить сферы профессиональной деятельности юристов-международников, выполняемой с применением иностранного языка.

2. Выявить лингвистические и профессиональные компетенции, необходимые и достаточные для профессиональной деятельности юриста-международника, которые должны быть сформированы в ходе обучения иностранному языку.

3. Определить психологические особенности речевой деятельности юриста-международника в ходе решения профессиональных задач.

4. Разработать требования для профессионально ориентированных учебных материалов.

Поставленные цели и задачи определили следующие методы исследования:

a) анкетирование выпускников международно-правового факультета, работающих по специальности, и ведущих специалистов в области юриспруденции из профессорско-преподавательского состава МГИМО;

b) лингвистический анализ текстов юридического характера;

c) изучение теоретических работ по методике и психологии преподавания иностранного языка;

d) анализ наиболее популярных учебных материалов, созданных носителями языка;

е) обобщение практического опыта преподавания английского языка на международноправовом факультете МГИМО;

f) экспериментальная проверка эффективности составленных учебных материалов.

Создание качественных профессионально ориентированных учебников для обучения иностранному языку юристов-международников предполагает, в первую очередь, анализ профессиональной деятельности, выполняемой ими с использованием иностранного языка. Исследование, начатое авторами данной статьи ещё в начале 2000-х годов, опиралось на анкетирование студентов старших курсов и выпускников международно-правового факультета МГИМО, работающих по специальности. Анкета включала следующие основные вопросы:

1. Какие виды работ вы выполняете с использованием иностранного языка?

2. Приходится ли вам проводить беседы с носителями языка? Если «ДА», то какие вопросы вы чаще всего обсуждаете? (Профессиональные? Повседневные? Общественно-политические?)

3. Какие трудности вы испытываете при выполнении профессиональных задач с использованием иностранного языка?

Анкетирование, которым было охвачено 119 человек, показало, что выпускники МГИМО выполняют следующие виды работы: 
- чтение и анализ юридических документов;

- письменный перевод документов с английского языка на русский и с русского на английский;

- составление документов юридического характера;

- устный двусторонний перевод бесед вышестоящих сотрудников;

- самостоятельное участие в переговорном процессе;

- свободные беседы и дискуссии на профессиональные темы.

Огромное значение для данного исследования имели личные беседы с ведущими специалистами в области юриспруденции, работавшими в МГИМО, среди которых были заслуженный юрист РФ доктор юридических наук профессор И.И. Веремеенко, заслуженный юрист РФ почётный доктор МГИМО РФ С.Н. Лебедев, доктор юридических наук профессор Г.П. Толстопятенко и другие.

Первоначальной гипотезой данной части исследования было мнение, что существуют специфические особенности восприятия и построения речевого высказывания профессиональным юристом. В ходе бесед данная гипотеза была подтверждена и расширена. В частности, было определено, что важной задачей обучения юриста, помимо сообщения знаний по различным отраслям права, является формирование юридического правового мышления.

Что касается языковой подготовки, было установлено, что как продуктивные (говорение и письмо), так и рецептивные (слушание и чтение) виды речевой деятельности юриста-международника имеют свои специфические черты, основными из которых является максимально точное восприятие устных сообщений и письменных текстов, а также формирование устного или письменного речевого высказывания не только абсолютно адекватно замыслу, но и способом, исключающим возможность различного толкования смысла высказывания.

Поясним последнее утверждение элементарным примером: “The editor of the newspaper decided to employ more talented reporters." Анализ данного простого предложения приводит к необходимости определить, что было решено: принять на работу больше репортёров (more reporters) или найти репортёров, которые более талантливы (more talented)? Если для обычного повседневного общения такие тонкости в высказываниях не имеют никакого значения, то в юридической практике они могут привести к серьёзным последствиям, если подобные разночтения в трактовке текста встречаются в формулировках документов, являющихся предметом судебного разбирательства.

Данное положение подтверждается многими исследованиями. Так, И.А. Богданова указывает, что неточности в тексте договора или грамматические ошибки могут привести к подаче судебных исков [2, с. 7]. Поддержку этого мнения мы находим и в исследовании Н.Д. Афанасьевой: «Неточное словоупотребление, нарушение законов языка в области права создают предпосылки для различного понимания закона, а значит, и различного применения его, то есть создаёт почву для произвола и беззакония» [1, с. 145].

Следует также отметить, что в процессе обучения иностранному языку, не предполагающего профессиональной направленности, основной целью является обучение порождению и восприятию речевых сообщений, поскольку повседневная деятельность с использованием иностранного языка в данном случае нацелена на обмен информацией. В ходе профессиональной деятельности с использованием иностранного языка главной проблемой является достижение какой-либо практической цели, само же речевое сообщение представляется средством её достижения. Порождение и восприятие высказываний происходит на фоне сложной мыслительной активности, предполагающей необходимость анализировать постоянно меняющуюся ситуацию общения, искать и формулировать новые аргументы, менять стратегию аргументации, искать новые пути достижения конечной цели деятельности.

Отсюда следует, что схема порождения речевого высказывания, а также психологическое содержание речевой деятельности, разработанные в трудах И.А. Зимней [9], на которых основывается обучение иностранному языку, в профессиональной деятельности становится намного более сложными и многоуровневыми. Становится очевидным, что в данных условиях участники общения не в состоянии концентрировать внимание на грамматическом и лексическом оформ- 
лении высказывания. Следовательно, в ходе профессионально ориентированного обучения иностранному языку лингвистические компетенции должны формироваться до уровня свободного владения.

Создание профессионально ориентированных учебных материалов также требует тщательного отбора грамматического и лексического материала, предлагаемого для активного усвоения. В научных трудах, посвящённых грамматическому оформлению юридического текста, закрепилось понятие «юридической грамматики». Однако, как утверждает И.А. Богданова, анализ теоретических трудов «позволяет утверждать, что большая часть материала описывает на примере юридических текстов правила и нормы стандартной практической грамматики английского языка» [2, с. 8]. В то же время исследование юридических документов (договоров, официальной переписки и т.п.), проведённое авторами данной статьи, показывает, что для юридических документов характерно употребление грамматических форм, которым уделяется мало внимания в учебных пособиях, не предполагающих профессиональной ориентации, а именно:

- употребление формы Present Perfect в придаточных предложениях времени и условия, подчёркивающей необходимость выполнения или завершения действия;

- употребление эмфатических конструкций типа "On no account do we agree to ...";

- употребление бессоюзных условных предложений с инверсией для выражения незначительной вероятности события: "Should somebody do something, somebody will ...";

- употребление форм сослагательного наклонения: "Propose that something (should) be done”;

- употребление номинативно-причастных абсолютных конструкций: “The terms of the contract having been fulfilled, the company is obliged ...."

Большое внимание при создании профессионально ориентированных учебных материалов должно уделяться отбору лексических единиц, предназначаемых для активного усвоения. Если в широко распространённых учебных пособиях предпочтение отдаётся эмоционально окрашенной лексике, характерной для художественного и публицистического стиля речи, то в профессионально ориентированных материалах для юристов упор должен быть сделан на лексике официального стиля, принятого в текстах юридического характера. При этом, по мнению авторов данной статьи, в ходе занятий общеязыковой подготовки не следует увлекаться изучением юридической терминологии, которая должна быть предметом дисциплины «Язык специальности» и требует привлечения юридического контекста. На наш взгляд, особое внимание должно уделяться выбору слов из синонимических рядов типа "state - claim - maintain", которые могут переводиться на русский язык одним и те же словом, а в английском языке имеют существенные различия в оттенках смысла.

Большое значение для создания качественных профессионально ориентированных материалов для обучения юристов-международников имеет отбор текстового материала, предназначенного для формирования коммуникативных компетенций. Было установлено, что наиболее рациональным является использование текстов общественно-политического характера, связанных с проблемами современности, допускающих их обсуждение с точки зрения права. Так, проблема использования водных ресурсов, которая широко освещается в средствах массовой информации, может обсуждаться не только как информационный материал по данной теме, но и в более широком аспекте, затрагивающем вопросы международного права в области использования ресурсов одного источника (например, реки) несколькими государствами. Данный подход в значительной степени повышает мотивацию обучения, поскольку он даёт возможность обучаемым использовать знания по специальным дисциплинам на занятиях по иностранному языку, представляет собой задачу, требующую интеллектуальных усилий, а также приводит к необходимости использовать интернет-ресурсы для поиска дополнительных сведений по изучаемому вопросу. Становится очевидным, что указанный подход к учебным материалам в значительной степени способствует профессионализации обучения.

На основе сказанного можно определить основные требования к профессионально ориентированным учебным материалам, которые должны содержать:

- упражнения для формирования речевых автоматизмов; 
- задания для формирования лингвистических компетенций;

- упражнения на перевод отдельных предложений и связных текстов с русского языка на английский;

- текстовой материал для формирования навыков чтения, а также компетенций общественнополитического, социально-культурного и профессионального общения.

Анализ учебных пособий, а также длительная работа с учебниками, созданными носителями английского языка серий "Headway" [18], [17], [16], “Face2Face” [15], [20], “Objective” [19], проведённая соавторами данной статьи, показывает, что данные материалы, естественно, не преследуют тех целей и задач, которым должны соответствовать профессионально ориентированные материалы. Дополнения, сопровождающие аутентичные учебники, также не могут обеспечить достаточно качественное обучение юристов-международников по той простой причине, что указанные учебники довольно часто переиздаются со значительными изменениями, вследствие чего создавать полноценные дополнения к ним в короткие сроки не представляется возможным.

Это приводит нас к необходимости разработки особых учебных материалов, отвечающих указанным выше требованиям и обеспечивающих последовательное поэтапное формирование лингвистических, общекультурных и профессиональных компетенций, необходимых юристумеждународнику. При этом представляется целесообразным создание серии учебников, каждый последующий этап которых базируется на усвоенном лексическом и грамматическом материале предыдущего. Данный подход позволяет осуществить основные методические принципы обучения (предъявления материала по принципу от простого к сложному, повторяемости материала, введения новых грамматических явлений на основе ранее усвоенной лексики, то есть соблюдения принципа доступности и посильности обучения и т.п.).

Примером серии профессионально ориентированных материалов могут служить учебники, разработанные Н.Н. Дианиной [7], [5]. Типовой Урок (Unit) данных учебников имеет следующую структуру:

1. Задания для развития навыков образования временных форм глагола.

2. Упражнения на употребление грамматических времен.

3. Лексико-грамматический перевод с русского языка на английский.

4. Тексты по актуальным вопросам современности для формирования навыков и умений чтения, а также коммуникативных компетенций.

5. Лексико-грамматические упражнения для отработки сложных грамматических конструкций, требующих повторного внимания, и лексических единиц, представляющих трудности при выборе слова.

6. Вопросы для дискуссионного обсуждения изучаемых тем.

7. Задания для написания эссе.

8. Раздел повторения и контроля усвоения лексического и грамматического материала.

Задания для развития навыков образования глагольных форм построены в виде трансформационных упражнений по моделям (образование вопросительной и отрицательной формы), которые должны быть отработаны до полного автоматизма в часы самостоятельной работы. Целью данных упражнений является предупреждение возникновения ошибок в речи или их коррекция в случае недостаточно прочного усвоения грамматического материала.

Упражнения на употребление грамматических времён представлены в виде заданий на раскрытие скобок сначала в отдельных предложениях, а затем в связных текстах. Такая подача материала представляется целесообразной, поскольку отдельные предложения выступают в роли объяснения и демонстрации употребления грамматических явлений. Их недостатком является присутствие своего рода «сигналов», указывающих на необходимость употребления той или иной грамматической формы, что до некоторой степени препятствует прочному усвоению материала. В связных текстах такого рода подсказок можно избежать и заставить обучаемых делать выбор грамматических форм с опорой на широкий контекст высказывания и таким образом обеспечить точное представление о значении изучаемых грамматических явлений. 
Грамматические упражнения на раскрытие скобок с глагольными формами являются многоцелевыми. Помимо обучения адекватному употреблению грамматических форм, они могут служить цели обучения анализу структуры предложения, что представляется исключительно важным для студентов-юристов, поскольку юридической текст изобилует формами пассивного залога, конструкциями с инфинитивом, причастием, герундием и придаточными предложениями.

Грамматические упражнения в виде связных текстов также позволяют провести на их основе ролевые игры или дискуссии, в ходе которых обучаемым даётся задание употреблять изучаемые грамматические явления в самостоятельных высказываниях. Таким образом обеспечивается формирование прочных грамматических навыков, составляющих большую часть необходимых лингвистических компетенций юриста-международника.

На основе сказанного можно определить основные требования к упражнениям данного вида:

- наличие интересного сюжета и /или проблемы для обсуждения;

- наличие сложных грамматических оборотов и придаточных предложений, требующих анализа структуры предложения для выполнения поставленной задачи;

- минимальное количество «сигналов» для употребления грамматических форм (now, already, just, yet, etc.);

- наличие вопросов для обсуждения текста или задания для ролевой игры по сюжету текста.

Упражнения на перевод с русского языка на английский имеют особое значение для обучения юристов, поскольку он является важным профессиональным умением юриста-международника. Основной проблемой здесь является то, что перевод практически исключён из школьных программ и абитуриенты, поступившие в вуз, оказываются неподготовленными к усвоению программы обучения. Кроме того, в школах сейчас укоренилось толерантное отношение к грамматическим ошибкам. Так, Н.Д. Гальскова и Н.И. Гез отмечают, что в школах даже с углублённым изучением иностранного языка допускается неточность в использовании языковых средств, поскольку «основная цель обучения иностранному языку - формирование способности к межкультурной коммуникации - исключает примат в учебном процессе грамматической прогрессии» [3, c. 132].

Указанный подход не может считаться приемлемым в обучении иностранному языку юристовмеждународников. По этой причине мы считаем, что лексико-грамматический перевод с русского языка на английский является важным средством обучения, так как он требует концентрации внимания на употреблении грамматических форм и изучаемых лексических единиц и тем самым представляется одним из способов закрепления учебного материала и предотвращения ошибок в речи. Поскольку лексико-грамматический перевод может быть построен не только в виде отдельных предложений, но и в виде связного текста, он может приближаться к некоторой модели реального речевого общения. Вследствие этого он может выступать не только как средство обучения адекватному употреблению грамматических форм и лексических единиц, но и говорению, так как, строя своё высказывание по какой-либо теме, студенты не могут избежать построения его на родном языке во внутренней речи с последующим его переводом на иностранный язык.

Следует также отметить, что письменный перевод с русского языка на английский является одним из средств обучения письму как виду речевой деятельности и не может быть полностью заменён на письменные задания типа эссе, поскольку в самостоятельных письменных высказываниях студенты обычно избегают употребления сложных грамматических форм и лексических единиц, что в значительной степени снижает ценность указанных заданий как средств обучения.

Как было указано выше, основными целями и задачами обучения юристов является сообщение знаний по различным отраслям права и формирование правового мышления. На первый взгляд эти задачи далеки от процесса преподавания иностранного языка, однако при ближайшем рассмотрении можно найти возможности достижения указанных целей.

Первая задача выполняется путём включения в программу обучения изучение классических произведений, связанных с историей и философией права. Представляется очевидным, что указанные материалы целесообразно включать не в корпус базовых учебников, а выносить их в аспект внеаудиторного домашнего чтения, что открывает широкие возможности для сообщения 
знаний по указанным вопросам, формирования навыков чтения, коммуникативных компетенций и работы над лексическим материалом, представляющим интерес для будущей профессиональной деятельности обучаемых. Примером такого материала может служить пособие Дианиной Н.Н. по книге Платона “The Laws” [8].

Выполнение второй задачи (формирование правового мышления) требует особого внимания. Исследователи данной проблемы, в частности А.И. Овчинников, отмечают, что основой правового мышления является логика [11]. В практике преподавания иностранного языка логика мышления может быть развита путём включения в процесс обучения дискуссий.

Следует отметить, что необходимо различать учебные дискуссии, организуемые в ходе изучения материалов базового учебника, и профессионально ориентированные дискуссии, являющиеся своего рода моделью профессиональной деятельности юристов и других специалистов, которые в ходе своей профессиональной деятельности принимают участие в переговорном процессе. К обычной учебной дискуссии не предъявляется высоких требований с точки зрения установленных правил ведения спора, так как здесь участники лишь обмениваются мнениями по обсуждаемым вопросам и рассогласованность их взглядов представляется лишь мотивом для высказывания. В дискуссиях подобного рода не требуется глубокого и всестороннего обоснования какой-либо точки зрения, высоких требований к логике высказываний не предъявляется и переубеждения оппонентов или приведения точек зрения к компромиссу не требуется.

К профессионально ориентированной дискуссии следует предъявлять иные требования, а именно:

а) адекватное определение понятий, являющихся предметом дискуссии, и варьирование объёма понятий в соответствии с целями высказывания;

b) логически верная последовательность предъявления аргументов для доказательства тезиса дискуссии и опровержения антитезиса;

c) определение достаточности / недостаточности аргументации для доказательства;

d) верность и обоснованность выводов в доказательстве;

е) определение логических ошибок в высказываниях оппонентов;

f) переубеждение оппонента или сведение спора к компромиссу.

Становится очевидным, что выполнение указанных требований невозможно без целенаправленной работы с использованием специально разработанных учебных материалов.

На наш взгляд, такие материалы должны содержать образцы дискуссий, демонстрирующих различные способы доказательства. Это позволяет обучаемым анализировать ход дискуссии, наблюдать, как можно применять различные способы доказательства тезиса, определять логические ошибки в доказательствах, менять тактику ведения дискуссии в зависимости от действий оппонента, управлять дискуссией. Далее на основе такого анализа студенты должны научиться самостоятельно составлять аналогичные диалоги. Специальные учебные материалы могут обеспечить постепенное нарастание трудности заданий и тем самым создавать условия для поэтапного формирования дискуссионных умений и, в конечном итоге, развития логики мышления, что является одной из важнейших составляющих профессиональной компетенции юриста-международника.

Примером такого учебного материала может служить пособие Дианиной H.H. "Plato 'Republic'. The Art of Discussion" [6].

Значительную часть профессиональной деятельности юриста-международника составляет оформление официальных и неофициальных документов (писем, меморандумов и т.п.). По этой причине определённое внимание в ходе обучения иностранному языку необходимо уделять формированию компетенций письма как вида речевой деятельности. Однако, как показывает практика, комплексные задания, посвящённые данному виду деятельности, целесообразно не включать в корпус базового учебника, а выделить их в специальное учебное пособие, поскольку они являются в достаточной степени типовыми и относятся в основном к предметному содержанию создаваемого студентами письменного высказывания. Примером такого материала является «Учебное пособие по обучению письму для студентов 4 курса МП факультета», разработанное соавтором данной статьи Лисовой Е.А. 
Существенное значение для качественного обучения английскому языку юристов-международников имеет вопрос, которому, к сожалению, в обычных учебниках никакого внимания не уделяется, а именно - пунктуация. Для документов юридического характера данный аспект является весьма важным, поскольку такой знак препинания, как запятая, часто несёт значительную смысловую нагрузку.

Ввиду того, что ссылки на правила употребления знаков препинания требуются в ходе всего обучения и являются по большей части задачей преподавателя, данному вопросу также целесообразно посвятить отдельное пособие, которое может быть подано в формате справочника. Примером такого материала служит «Введение в пунктуацию английского языка», составленное соавторами данной статьи М.А. Колосовской и Н.А. Сергейчевой.

Значительную роль в создании профессионально ориентированных учебных материалов играет экспериментальная проверка их качества, что и было сделано соавторами данной статьи. Задачами экспериментальной проверки являлось:

a) определение достаточности / недостаточности количества и объёма упражнений различного вида для достижения конечных целей учебных материалов;

b) выявление недостатков в очередности подачи материала;

c) определение общей эффективности материалов для формирования лингвистических, коммуникативных и профессиональных компетенций;

d) оценка материалов как преподавателями, так и студентами.

В ходе проверки был выявлен целый ряд недостатков. В частности, было установлено, что в ходе работы с формами Present Perfect Simple нецелесообразно включать в упражнения случаи употребления данной формы в придаточных предложениях с союзом 'since' (Since he has been here, he has done ...), которые представляют собой значительную (а в некоторых случаях и непреодолимую) трудность в усвоении материала. Если же данную форму представить в разделе Present Perfect Progressive как употребление формы 'Simple' вместо 'Progressive' с глаголами состояния, особых трудностей в усвоении материала не возникает.

Было также определено, что более или менее твёрдое усвоение таких сложных грамматических явлений, как инверсия в эмфатических конструкциях (Only then did they ...), происходит после третьего предъявления материала с перерывом более двух месяцев.

Ещё одним из недостатков учебников, выявленных в ходе проверки, было распределение грамматических тем по сложности усвоения. Так, по мнению как преподавателей, так и студентов, на конец семестра не должен приходиться сложный материал, требующий значительных интеллектуальных усилий для усвоения и тщательной отработки.

Было также отмечено, что на продвинутых этапах обучения, где особое внимание уделяется таким видам учебной деятельности, как дискуссии, свободные высказывания по темам обучения, ролевые и деловые игры, увеличивается количество ошибок в речи, поскольку указанные виды работ требуют значительных интеллектуальных усилий, вследствие чего ослабевает внимание, направленное на языковое оформление высказывания.

Анализ проводился на основании результатов экзамена за 4 семестр (2 курс) и устного зачета за 7 семестр (4 курс), а также ролевых и деловых игр, проводившихся в течение тех же семестров. В расчёт принимались показатели студентов 2 курса в группах авторов данной статьи Н.Н. Дианиной и Н.А. Сергейчевой (4 группы, 27 человек) и тех же студентов на четвёртом курсе, обучавшихся в группах М.А. Колосовской и Е.А. Лисовой. Объём данной статьи не позволяет привести все данные эксперимента, поэтому мы ограничимся полученными выводами.

Было установлено, что студенты, имеющие оценки успеваемости в пределах B82 - A90, на втором курсе бакалавриата в подготовленном устном высказывании допускали 4-7 ошибок, в ролевых играх - 5-10 ошибок, в устном переводе предложений с русского языка на английский - 1-3 ошибки. На четвёртом курсе бакалавриата у данной категории студентов наблюдалось увеличение ошибок в количестве 2-3 по всем пунктам проверки.

Студенты, имеющие оценки успеваемости в пределах D67 - 74, на втором курсе бакалавриата в подготовленном устном высказывании допускали 8-10 ошибок, в ролевых играх - 9-12, в пере- 
воде предложений с листа - до 6 ошибок. На четвёртом курсе у данной категории студентов наблюдалось значительное увеличение количества ошибок по всем аспектам проверки. При этом необходимо отметить, что у всех категорий студентов наблюдались ошибки в порядке слов в вопросительных предложениях, употреблении грамматических времён и артиклей.

Это свидетельствует о том, что на продвинутых этапах обучения должна проводиться работа по поддержанию навыков устной речи. Для выполнения указанной задачи можно рекомендовать включение в базовый учебник упражнений на употребление грамматических времён и перевод с русского языка на английский, поскольку именно эти виды работы требуют концентрации внимания на грамматической форме.

В общем и целом, экспериментальная проверка показала высокую эффективность представленных материалов. Все выявленные недостатки были устранены в конечном варианте учебников.

На основании сказанного можно сделать вывод, что создание качественных профессионально ориентированных учебных материалов должно основываться на анализе профессиональной деятельности выпускников университета, отборе необходимого и достаточного грамматического и лексического материала, разработке системы упражнений в соответствии с целями и задачами пособий и экспериментальной проверке качества материалов.

\section{(C) Дианина Н.Н., Колосовская М.А., Лисова Е.А., Сергейчева Н.А., 2021}

\section{Список литературы}

1. Афанасьева Н.Д. Обучение культуре деловой речи иностранных студентов юридической специальности. Дисс. канд. пед. наук. Москва, РУДН, 2009. 190с.

2. Богданова И.А. Грамматические особенности организации юридического текста: роль и место юридической грамматики при обучении языку специальности юристов-международников // Юридический английский язык: предмет, исследования практика. Сб. материалов круглого стола международной научно-практической конференции / под ред. М.А. Голубцовой. Москва : МГИМО-Университет, 2019. 98с.

3. Гальскова Н.Д. Теория обучения иностранным языкам. Лингводидактика и методика : учебное пособие для студ. линг. ун-тов и фак. ин. яз. высш. пед. учебн. заведений / Н.Д. Гальскова, Н.И. Гез. М.: Издательский центр «Академия», 2006. 336c.

4. Гринева М.В. Формирование профессионального языкового дискурса экономистов-международников средствами домашнего чтения. Дисс. канд. пед. наук. Москва, 2018. 221с.

5. Дианина Н.Н. Аутентичный английский для продвинутого этапа обучения : учебное пособие / Н.Н. Дианина ; МГИМО МИД России. Москва : МГИМО-Университет, 2015. - 400с.

6. Дианина Н.Н. Платон «Государство»: искусство дискуссии : учебное пособие / Н.Н. Дианина ; МГИМО МИД России. Москва : МГИМО-Университет, 2009. 141с.

7. Дианина Н.Н. Учебник английского языка для среднего этапа обучения : учебное пособие / Н.Н. Дианина ; МГИМО МИД России. Москва : МГИМО-Университет, 2018. 281с.

8. Дианина Н.Н. Учебное пособие для студентов 1-2 курсов международно-правового факультета по книге Платона «Законы» : учебное пособие / Н.Н. Дианина ; МГИМО МИД России. Москва : МГИМО-Университет, 1999. 98с.

9. Зимняя И.А. Психология обучения неродному языку. М.: Рус. яз., 1989. 219с.

10. Кизима А.А. Организационно-педагогические условия профессиональной языковой пропедевтики экономистовмеждународников в высшей школе. Дисс. канд. пед. наук. Москва, 2019. 201с.

11. Овчинников А.И. Правовое мышление. Дисс. докт. юридич. наук. Краснодар, 2004. 512с.

12. Павлова А.Н. Ранняя языковая профессионализация экономистов-международников (на примере итальянского языка). Дисс. канд. пед. наук. Москва, 2019. 188с.

13. Рекош К.Х. Французский язык как вербализатор западно-европейского правового знания (от истоков до дискурса права Европейского союза. Автореф. дисс. док. пед. наук. Москва, РУДН, 2018. 45с.

14. Хомякова Н.П. Контекстная модель формирования иноязычной коммуникативной компетенции студентов неязыкового вуза: французский язык. Автореф. дисс. докт. пед. наук. Москва, МГЛУ, 2011. 48с.

15. Chris Redston \& Gillie Cunningham. Face2Face Upper Intermediate. Cambridge : Cambridge University Press, 2007. 160p.

16. Liz \& John Soars. New Headway Advanced. Oxford : Oxford University Press, 2003. 160p.

17. Liz \& John Soars. New Headway Intermediate. Oxford : Oxford University Press, 1996. 159p.

18. Liz \& John Soars. New Headway Pre-Intermediate. Oxford : Oxford University Press, 2000. 144p.

19. Michael Black \& Annette Capel. Objective Advanced Self-study Student's Book. Cambridge : Cambridge University Press, 2006. 207p. 
20. Jillie Cunningham \& Jan Bell. Face2Face Advanced. Cambridge : Cambridge University Press, 2010. 160p.

\section{References}

1. Afanas'eva, N.D. Obuchenie kul'ture delovoi rechi inostrannykh studentov iuridicheskoi spetsial'nosti (Teaching foreign students of law the art of formal styles of speech). Diss. kand. ped. nauk. Moskva, RUDN, 2009. 190s.

2. Bogdanova, I.A. Grammaticheskie osobennosti organizatsii iuridicheskogo teksta: rol' i mesto iuridicheskoi grammatiki pri obuchenii iazyku spetsial'nosti iuristov-mezhdunarodnikov (Grammatical features of the organization of the legal text: role and place of legal grammar in the teaching of the language in the field of international law) // Iuridicheskii angliiskii iazyk: predmet, issledovaniia praktika. Sb. materialov kruglogo stola mezhdunarodnoi nauchno-prakticheskoi konferentsii (English Legal Language: subject, studies and practice. Proceedings of the Round Table of the International Scientific and Practical Conference)/ pod red. M.A. Golubtsovoi. Moskva : MGIMO-Universitet, 2019. 98s.

3. Gal'skova, N.D., Gez N.I. Teoriia obucheniia inostrannym iazykam. Lingvodidaktika i metodika : uchebnoe posobie dlia stud. ling. un-tov i fak. in. iaz. vyssh. ped. uchebn. zavedenii (Theory of Foreign Language Education. Linguadidactics and Methodology: Training Manual for Linguistic University students and students of Foreign Language Departments of Higher Pedagogical Education Institutes) / N.D. Gal'skova, N.I. Gez. M.: Izdatel'skii tsentr «Akademiia», 2006. 336s.

4. Grineva, M.V. Formirovanie professional'nogo iazykovogo diskursa ekonomistov-mezhdunarodnikov sredstvami domashnego chteniia (Building skills of professional language discourse of international economists by means of home reading). Diss. kand. ped. nauk. Moskva, 2018. 221s.

5. Dianina, N.N. Autentichnyi angliiskii dlia prodvinutogo etapa obucheniia : uchebnoe posobie (Authentic English for Advanced Learners) / N.N. Dianina ; MGIMO MID Rossii. Moskva : MGIMO-Universitet, 2015. 400s.

6. Dianina, N.N. Platon "Gosudarstvo»: iskusstvo diskussii : uchebnoe posobie (Plato. "Republic": the Art of Discussion) / N.N. Dianina ; MGIMO MID Rossii. Moskva : MGIMO-Universitet, 2009. 141s.

7. Dianina, N.N. Uchebnik angliiskogo iazyka dlia srednego etapa obucheniia : uchebnoe posobie (English Course Book for Intermediate students) / N.N. Dianina ; MGIMO MID Rossii. Moskva : MGIMO-Universitet, 2018. 281s.

8. Dianina, N.N. Uchebnoe posobie dlia studentov 1-2 kursov mezhdunarodno-pravovogo fakul'teta po knige Platona «Zakony» : uchebnoe posobie (Training manual for students of 1-2 courses of the International Law Faculty on the book by Plato "Laws") / N.N. Dianina ; MGIMO MID Rossii. Moskva : MGIMO-Universitet, 1999. 98s.

9. Zimniaia, I.A. Psikhologiia obucheniia nerodnomu iazyku. (Psychology of non-native language learning) M.: Rus. iaz., 1989. 219s.

10. Kizima, A.A. Organizatsionno-pedagogicheskie usloviia professional'noi iazykovoi propedevtiki ekonomistov-mezhdunarodnikov $v$ vysshei shkole. (Organizational and pedagogical conditions for the professional development of international economists in higher education) Diss. kand. ped. nauk. Moskva, 2019. 201s.

11. Ovchinnikov, A.I. Pravovoe myshlenie. (Legal thinking) Diss. dokt. iuridich. nauk. Krasnodar, 2004. 512s.

12. Pavlova, A.N. Ranniaia iazykovaia professionalizatsiia ekonomistov-mezhdunarodnikov (na primere ital'ianskogo iazyka) (Early language professionalization of international economists (using the example of the Italian Language)). Diss. kand. ped. nauk. Moskva, 2019. 188s.

13. Rekosh, K.H. Frantsuzskii iazyk kak verbalizator zapadno-evropeiskogo pravovogo znaniia (ot istokov do diskursa prava Evropeiskogo soiuza). (French as a recruiter of Western European legal knowledge (from the origins to the discourse of European Law)) Avtoref. diss. dok. ped. nauk. Moskva, RUDN, 2018. 45s.

14. KHomiakova, N.P. Kontekstnaia model' formirovaniia inoiazychnoi kommunikativnoi kompetentsii studentov neiazykovogo vuza: frantsuzskii iazyk. (Contextual model of the formation of foreign communication competence of students of nonlinguistic higher education institution: French) Avtoref. diss. dokt. ped. nauk. Moskva, MGLU, 2011. 48s.

15. Chris Redston \& Gillie Cunningham. Face2Face Upper Intermediate. Cambridge : Cambridge University Press, 2007. 160p.

16. Liz \& John Soars. New Headway Advanced. Oxford : Oxford University Press, 2003. 160p.

17. Liz \& John Soars. New Headway Intermediate. Oxford : Oxford University Press, 1996. 159p.

18. Liz \& John Soars. New Headway Pre-Intermediate. Oxford : Oxford University Press, 2000. 144p.

19. Michael Black \& Annette Capel. Objective Advanced Self-study Student's Book. Cambridge : Cambridge University Press, 2006. 207 .

20. Jillie Cunningham \& Jan Bell. Face2Face Advanced. Cambridge : Cambridge University Press, 2010. 160p.

\section{Сведения об авторах:}

Дианина Наталия Николаевна - кандидат педагогических наук, доцент, доцент кафедры английского языка №8 МГИМО МИД России. Сфера научных и профессиональных интересов: методика преподавания иностранных языков, грамматика английского языка, межкультурная коммуникация, риторика. E-mail: n.dianina.n@gmail.com

Колосовская Марина Анатольевна - старший преподаватель кафедры английского языка №8 МГИМО МИД России. Сфера научных и профессиональных интересов: грамматика английского языка, межкультурная коммуникация, инновационные методы преподавания. E-mail: kolosovskaya.1958@mail.ru 
Лисова Елизавета Анатольевна - старший преподаватель кафедры английского языка №8 МГИМО МИД России. Сфера научных и профессиональных интересов: методика преподавания иностранных языков, теория перевода, грамматика английского языка.

E-mail: elizaveta.lisova@gmail.com

Сергейчева Наталия Александровна - старший преподаватель кафедры английского языка №8 МГИМО МИД России. Сфера научных и профессиональных интересов: грамматика английского языка, фонетика английского языка, межкультурная коммуникация.

E-mail: Sergeytcheva@hotmail.com

\section{About the authors:}

Natalia N. Dianina - PhD, Assistant Professor of English Language Department №8, MGIMO University (Moscow, Russia). Spheres of research and professional interest: methodology of foreign language teaching, English grammar, cross-cultural communication, rhetoric. E-mail: n.dianina.n@gmail.com

Marina A. Kolosovskaia - Senior teacher of English Language Department №8, MGIMO University (Moscow, Russia). Spheres of research and professional interest: English grammar, cross-cultural communication, innovative methods of teaching. E-mail: kolosovskaya.1958@mail.ru

Elizaveta A. Lisova - Senior teacher of English Language Department №8, MGIMO University (Moscow, Russia). Spheres of research and professional interest: methodology of foreign language teaching, theory of translation, English grammar. E-mail: elizaveta.lisova@gmail.com

Natalia A. Sergeitcheva - Senior teacher of English Language Department №8, MGIMO University (Moscow, Russia). Spheres of research and professional interest: English grammar, English phonetics, cross-cultural communication. E-mail: Sergeytcheva@hotmail.com 